\title{
Taxane-induced sensory peripheral neuropathy is associated with an SCN9A single nucleotide polymorphism in Japanese patients
}

Yuko Tanabe ${ }^{1,2^{*}}$, Seiji Shiraishi ${ }^{3}$, Kenji Hashimoto ${ }^{1}$, Kazutaka Ikeda $^{4}$, Daisuke Nishizawa ${ }^{4}$, Junko Hasegawa ${ }^{4}$, Akihiko Shimomura ${ }^{1,2}$, Yukinori Ozaki ${ }^{2}$, Nobuko Tamura ${ }^{5}$, Mayu Yunokawa ${ }^{1}$, Kan Yonemori ${ }^{1}$, Toshimi Takano ${ }^{2}$, Hidetaka Kawabata ${ }^{5}$, Kenji Tamura' ${ }^{1}$ Yasuhiro Fujiwara ${ }^{1}$ and Chikako Shimizu ${ }^{6}$

\begin{abstract}
Background: Sodium channels located in the dorsal root ganglion, particularly Nav1.7 and Nav1.8, encoded by SCN9A and SCN10A, respectively, act as molecular gatekeepers for pain detection. Our aim was to determine the association between TIPN and SCN9A and SCN10A polymorphisms.

Methods: Three single nucleotide polymorphisms (SNPS) in SCN9A and two in SCN10A were investigated using wholegenome genotyping data from 186 Japanese breast or ovarian cancer patients classified into two groups as follows: cases that developed taxane-induced grade $2-3$ neuropathy $(N=108)$ and controls $(N=78)$ with grade $0-1$ neuropathy. Multiple logistic regression analyses were conducted to evaluate associations between TIPN and SNP genotypes.

Results: SCN9A-rs13017637 was a significant predictor of grade 2 or higher TIPN (odds ratio $(O R)=3.463 ; P=0.0050$ ) after correction for multiple comparisons, and precision was improved when only breast cancer patients were included (OR 5.053, $P=0.0029$ ). Moreover, rs 13017637 was a significant predictor of grade 2 or higher TIPN 1 year after treatment (OR 3.906, $P=0.037$ ), indicating its contribution to TIPN duration.
\end{abstract}

Conclusion: SCN9A rs13017637 was associated with the severity and duration of TIPN. These findings are highly exploratory and require replication and validation prior to any consideration of clinical use.

Keywords: Breast and ovarian cancer, rs13017637, SCN9A, SCN10A, Taxane-induced peripheral neuropathy

\section{Background}

Taxanes, such as paclitaxel and docetaxel, are used to treat a variety of tumor, especially breast and ovarian cancer $[1$, 2]. The common non-hematologic toxicity associated with these drugs is peripheral neuropathy. Taxane-induced

\footnotetext{
* Correspondence: ytanabe@toranomon.gr.jp

'Department of Breast and Medical Oncology, National Cancer Center Hospital, 5-1-1 Tsukiji, Chuo-ku, Tokyo 104-0045, Japan

${ }^{2}$ Department of Medical Oncology, Toranomon Hospital, 2-2-2 Toranomon, Minato-ku, Tokyo 105-8470, Japan

Full list of author information is available at the end of the article
}

peripheral neuropathy (TIPN) can be dose limiting, which would affect treatment efficacy, and can worsen quality of life. As susceptibility to TIPN differs greatly among patients $[3,4]$, predicting patient risk could improve therapeutic efficacy and quality of life by personalizing treatment.

To date, several genes have been reported as potential risk factors for TIPN, including those associated with transport (e.g. $A B C B 1$ ) [5-7], metabolism (e.g. CYP3A4, CYP3A5, and $C Y P 2 C 8$ ) [5, 8-10], development and regeneration in the nervous system (e.g. EPHA4 and EPHA5) [11], myelination in peripheral nerve (FGD4) [11], and $\beta$ -

C C The Author(s). 2020 Open Access This article is licensed under a Creative Commons Attribution 4.0 International License, which permits use, sharing, adaptation, distribution and reproduction in any medium or format, as long as you give appropriate credit to the original author(s) and the source, provide a link to the Creative Commons licence, and indicate if changes were made. The images or other third party material in this article are included in the article's Creative Commons licence, unless indicated otherwise in a credit line to the material. If material is not included in the article's Creative Commons licence and your intended use is not permitted by statutory regulation or exceeds the permitted use, you will need to obtain permission directly from the copyright holder. To view a copy of this licence, visit http://creativecommons.org/licenses/by/4.0/ The Creative Commons Public Domain Dedication waiver (http://creativecommons.org/publicdomain/zero/1.0/) applies to the data made available in this article, unless otherwise stated in a credit line to the data. 
tubulin (TUBB2A) [12]. Thus, many pharmacogenetic studies have attempted to identify polymorphisms that contribute to variations in susceptibility to TIPN; however, current data are insufficient to make genetic testings routine for these variants.

Many different hypotheses regarding the mechanisms of sensory TIPN have been generated, including excessive microtubule assembly, which causes the abnormal accumulation of disorganized microtubules disrupting normal cellular activities such as axonal transport and Schwann cell function; however, this process is still unclear [13, 14]. Voltage-gated sodium channels (VGSCs) located in the dorsal root ganglion (DRG), particularly Nav1.7 and Nav1.8, encoded by SCN9A and SCN10A, respectively, have important roles in the pathogenesis of human neuropathic pain [15-17]. VGSC mutations were reported to be associated with diseases of both the central and peripheral nervous systems [18]. Especially, mutations in SCN9A play a significant role in nociception signaling and have been associated with channelopathy-associated insensitivity to pain and paroxysmal extreme pain disorder, whereas the protein encoded by SCN1OA is a tetrodotoxin-resistant sodium channel (SCNA) subunit that might be involved in painful peripheral neuropathy (PN) $[15,16]$. Moreover, dorsal ganglionic Nav1.7 is upregulated in rats and humans administered paclitaxel. Blocking the function of Nav1.7 was found to partially attenuate paclitaxel-induced hyperalgesia in rats. This suggests that this protein is involved in paclitaxel-induced neuropathic pain $[19,20]$. However, no pharmacogenetic studies have focused on the association between TIPN and SCNA in a clinical setting. Therefore, we investigated the effects of SNPs in genes encoding VGSC using a prospective cohort of well-characterized breast or ovarian cancer patients treated with taxanes.

\section{Methods \\ Patients}

Japanese women with breast or ovarian cancer receiving taxane regimens were enrolled in a prospective observational study to evaluate taxane-related toxicity and to explore gene variants associated with TIPN by performing a genome wide association study (UMIN000005294) [7]. The eligibility criteria are shown in previous study [7]. All patients provided written informed consent for adjuvant treatment and DNA collection for genetic analysis. The study was conducted in accordance with the Declaration of Helsinki and was approved by the local institutional review board (protocol number: 2013-199).

\section{Treatment}

Breast cancer patients were treated with 4 cycles of cyclophosphamide $\left(600 \mathrm{mg} / \mathrm{m}^{2}\right)$ and doxorubicin $(60$ $\mathrm{mg} / \mathrm{m}^{2}$ ) (AC) or cyclophosphamide $\left(500 \mathrm{mg} / \mathrm{m}^{2}\right)$ with epirubicin $\left(100 \mathrm{mg} / \mathrm{m}^{2}\right)$ and 5-fluorouracil $\left(500 \mathrm{mg} / \mathrm{m}^{2}\right)$ (CEF) every 3 weeks. Subsequently, paclitaxel $\left(80 \mathrm{mg} / \mathrm{m}^{2}\right.$, weekly) or docetaxel $\left(75 \mathrm{mg} / \mathrm{m}^{2}\right.$, every 3 weeks) was administered for 12 weeks. In addition, 4 cycles of cyclophosphamide $\left(600 \mathrm{mg} / \mathrm{m}^{2}\right.$, day1) and docetaxel $(75 \mathrm{mg} /$ $\mathrm{m}^{2}$, day1) every 3 weeks (CPA + DTX) was also an option for breast cancer treatment. Patients positive for HER2 by immunohistochemistry or gene amplification analysis received trastuzumab concurrently with paclitaxel (weekly or every 3 weeks). Ovarian cancer patients were treated with 6 cycles of paclitaxel $\left(175 \mathrm{mg} / \mathrm{m}^{2}\right)$ and carboplatin (AUC6, day 1) every 3 weeks (Tri TC), or paclitaxel $\left(80 \mathrm{mg} / \mathrm{m}^{2}\right.$, day $\left.1,8,15\right)$ and carboplatin (AUC6, day 1) every 3 weeks (dose-dense TC).

\section{TIPN evaluation}

Neuropathy was prospectively evaluated at baseline before paclitaxel treatment, at week 7 , within 3 weeks at or after the final dose, and 1 year after the last dose of paclitaxel, based on the National Cancer Institute Common Terminology Criteria for Adverse Events 4.0 [21]. Evaluators of PN are five medical oncologists who are trained in toxicity assessment. One patient was evaluated by the same physician.

\section{Genotyping}

A 10-mL blood sample was collected from each patient upon enrollment. Genotyping assays were performed for eligible patients with sufficient DNA in the sample. DNA was extracted from whole-blood samples using standard procedures. The extracted DNA was dissolved in TE buffer $(10 \mathrm{mM}$ tris- $\mathrm{HCl}$ and $1 \mathrm{mM}$ EDTA, $\mathrm{pH} 8.0)$ and the concentration was adjusted to $100 \mathrm{ng} / \mathrm{ml}$ for wholegenome genotyping using a NanoDrop ND-1000 Spectrophotometer (NanoDrop Technologies, Wilmington, DE, USA). To analyze polymorphisms within and around the SCN9A and SCN10A gene regions, whole-genome genotype data were used. Whole-genome genotyping was performed using the Infinium assay II and the iScan system (Illumina, San Diego, CA) according to the manufacturer's instructions. The OmniExpressExome-8 v1.1 BeadChip was used to genotype entire samples. The BeadChip included a number of probes that was specific to copy number variation markers, but most were for SNP markers on human autosomes or sex chromosomes. Approximately 900,000 SNP markers were included in the BeadChip. After whole-genome genotyping, data were analyzed using GenomeStudio Genotyping module v1.6.3 (Illumina) to evaluate the quality of results, and genotype data for SNPs with SCN9A and SCN10A gene annotations were extracted. The analyzed SNPs were SCN9As (rs7607967, rs12994338, and rs13017637) and SCN10A (rs12632942 and rs6795970), which were evaluated in previous reports [17, 22-25]. 


\section{Statistical analysis}

The primary objective was to evaluate the association between TIPN grade and $S C N 9 A$ and $S C N 10 A$ variants. The association between genetic variants and the risk of grade 2-3 TIPN was assessed by logistic regression analysis with adjustments for confounding clinical covariates. The dependent variable was maximum TIPN grade (grades $0-1$ or 2-3), and the independent variables were type of cancer (breast cancer vs. ovarian cancer), age (< 60 vs. $\geq 60$ years), TIPN latency, and genotype data for each SNP; alternatively, the dependent variable was TIPN grade 1 year after treatment, and the independent variables were maximum TIPN grade, TIPN duration, and genotype data for each SNP. TIPN duration is defined as time from onset of PN until disappearance of $\mathrm{PN}$ or at 1 year of treatment. We preliminarily planned to dichotomize age at 60 years and compare TIPN, referring to our previous study [3]. For the selected polymorphisms, we considered either an additive, dominant, or recessive model. Odds ratios (ORs) and their 95\% confidence intervals (95\% CIs) were used to estimate relative risk. $S C N 9 A$ and $S C N 10 A$ frequencies were assessed for concordance with expectations based on the HardyWeinberg equilibrium (HWE), using the chi-square test and Fisher's exact test. Given the sample size of cases (108 patients with grade 2-3 TIPN) and controls (78 patients with grade $0-1$ TIPN) and assuming a power of $85 \%$, the level of significance was 0.1 . Power calculations were performed using $G^{*}$ power software v3.1.9.2. All analyses were performed using the highest grade of treatment-related sensory peripheral neuropathy. Patients for whom taxane-based chemotherapy was discontinued due to adverse events, except neuropathy, were excluded from the analyses. Multiple comparisons were accounted for by using Bonferroni adjustment $\alpha=0.05$ (corrected alpha $(\alpha=0.05 / 5=0.01)$ ). A two-sided adjusted $P$-value of $<0.05$ was considered statistically significant, and all analyses were performed using SAS software (version 9.2; SAS Institute, Cary, NC, USA).

\section{Results}

\section{Patient characteristics}

We analyzed 186 of 221 Japanese women enrolled between February 2011 and October 2013 at the two study sites. Thirty-five patients were excluded, including patients lost to follow-up $(N=16)$, patients not treated with taxane $(N=9)$, patients with a history of prior taxane use $(N=5)$, patients for whom chemotherapy was discontinued due to adverse events other than peripheral neuropathy $(N=1)$, and other reasons $(N=4)$. The demographic and clinical characteristics of patients are listed in Table 1. The median age was 52 years (range, 25-81 years). The number of breast and ovarian cancer patients was 135 and 51, respectively. One hundred and seventy-seven patients received paclitaxel treatment, whereas nine patients received docetaxel. Among 186 patients studied, for $38(20 \%)$ and $16(8 \%)$, the dose was reduced or treatment was terminated because of neuropathy or reasons other than neuropathy, respectively. Maximum grades of TIPN were $0(N=2,1 \%), 1(N=76$, $41 \%), 2(N=91,49 \%)$, and $3(N=17,9 \%)$.

\section{Distribution of SCN9A and SCN10A genotypes}

Genotypes in each SNP are listed in Table 1. Genotyping call rates by SNP and patient were estimated. We confirmed that both call rates (by SNP and patient) were $>$ 0.95 and all SNPs and samples were included in the analyses. The distributions of the SCN9A (rs7607967, rs12994338, and rs13017637) and SCN1OA (rs12632942 and rs6795970) polymorphisms were all in accordance with the HWE (data not shown).

\section{Association between SNPs and maximum TIPN grade}

Results of dominant genetic model were reported in text and tables. Results of other models were not shown because they were not statistically significant. Of the five SNPs evaluated, SCN9A-rs13017637 was significantly associated with grade 2 or higher TIPN in all patients (OR, 3.463, $P=0.0050 ;$ Table 2). In addition, SCN9Ars 13017637 was significantly associated with grade 2 or higher TIPN among the 135 breast cancer patients (OR, 5.053, $P=0.0029$; Table 2).

\section{Association between SNPs and TIPN grade 1 year after taxane}

Of the five SNPs evaluated, SCN9A-rs13017637 was significantly associated with grade 2 or higher TIPN in all patients (OR, 3.906, $P=0.037$; Table 2). However, no SNPs were significantly associated with grade 2 or higher TIPN among the 135 breast cancer patients.

\section{Discussion}

We evaluated the effect of sodium channel-related genes on TIPN development in breast or ovarian cancer patients treated with taxane. Multiple logistic regression revealed that SCN9A-rs13017637 was significantly associated with grade 2 or higher TIPN. It was also significantly associated with grade 2 or higher TIPN 1 year after the completion of taxane-based therapy. To our knowledge, this is the first study demonstrating that SNPs of sodium channel-related genes are associated with increased TIPN severity in Japanese patients treated with taxane.

Sodium channels in the DRG function as molecular gatekeepers of pain detection at peripheral nociceptors. Nine sodium channel subunits have been identified (Nav1.1-Nav1.9), each with a unique central and peripheral nervous system distribution. Gain-of-function (GOF) mutations in SCN9A, encoding Nav1.7, cause 
Table 1 Patient characteristics

\begin{tabular}{|c|c|c|c|}
\hline & $\begin{array}{l}\text { All patients } \\
(N=186)\end{array}$ & $\begin{array}{l}\text { Cases } \\
\text { TIPN Gr 2-3 } \\
(N=108)\end{array}$ & $\begin{array}{l}\text { Control } \\
\text { TIPN Gr 0-1 } \\
(N=78)\end{array}$ \\
\hline \multicolumn{4}{|l|}{ Cancer Type } \\
\hline Breast ca. ${ }^{a}$ & 135 & 67 & 68 \\
\hline Ovarian ca. ${ }^{a}$ & 51 & 41 & 10 \\
\hline $\begin{array}{l}\text { Age (year) } \\
\text { median (range) }\end{array}$ & $52(25-81)$ & $56(25-81)$ & $48(27-73)$ \\
\hline \multicolumn{4}{|l|}{ Chemotherapy regimen ${ }^{b}$} \\
\hline AC or CEF f/b wPTX & $126(68 \%)$ & $67(62 \%)$ & $59(77 \%)$ \\
\hline$A C$ or CEF f/b DTX & $5(3 \%)$ & 0 & $5(6 \%)$ \\
\hline$C P A+D T X$ & $4(2 \%)$ & 0 & $4(5 \%)$ \\
\hline Dose dense TC & $39(21 \%)$ & $34(32 \%)$ & $5(6 \%)$ \\
\hline Tri TC & $12(6 \%)$ & $7(6 \%)$ & $5(6 \%)$ \\
\hline \multicolumn{4}{|l|}{ Maximum grade of TIPN ${ }^{c}$} \\
\hline 0 & $2(1 \%)$ & $0(0 \%)$ & $2(3 \%)$ \\
\hline 1 & $76(41 \%)$ & $0(0 \%)$ & 76 (97\%) \\
\hline 2 & $91(49 \%)$ & $91(84 \%)$ & $0(0 \%)$ \\
\hline 3 & $17(9 \%)$ & $17(16 \%)$ & $0(0 \%)$ \\
\hline \multicolumn{4}{|l|}{$\begin{array}{l}\text { Cumulative taxane dose }\left(\mathrm{mg} / \mathrm{m}^{2}\right) \\
\text { median (range) }\end{array}$} \\
\hline PTX & $\begin{array}{l}960(560-1440) \\
(N=177)\end{array}$ & $\begin{array}{l}960(560-1440) \\
(N=108)\end{array}$ & $960(688-1440)(N=69)$ \\
\hline DTX & $\begin{array}{l}300(270-400) \\
(N=9)\end{array}$ & - & $\begin{array}{l}300(270-400) \\
(N=9)\end{array}$ \\
\hline $\begin{array}{l}\text { Time to develop TIPN (days) } \\
\text { median (range) }\end{array}$ & $33(7-79)$ & $28(7-79)$ & $35(7-77)$ \\
\hline $\begin{array}{l}\text { Duration of TIPN (days) } \\
\text { median (range) }\end{array}$ & $446(0-1416)$ & $455(70-1395)$ & $416(0-1327)$ \\
\hline \multicolumn{4}{|l|}{ Grade of TIPN at 1 year after taxane } \\
\hline 0 & $44(24 \%)$ & $10(9 \%)$ & $34(44 \%)$ \\
\hline 1 & $74(40 \%)$ & $38(35 \%)$ & $36(46 \%)$ \\
\hline 2 & $41(22 \%)$ & $41(38 \%)$ & $0(0 \%)$ \\
\hline 3 & $2(1 \%)$ & $2(2 \%)$ & $0(0 \%)$ \\
\hline unknown & $25(13 \%)$ & $17(16 \%)$ & $8(10 \%)$ \\
\hline Full dose administration of taxane & $132(71 \%)$ & $63(58 \%)$ & $69(88 \%)$ \\
\hline Dose reduction or termination of taxane due to TIPN & $38(20 \%)$ & $35(32 \%)$ & $3(4 \%)$ \\
\hline Dose reduction or termination due to other reasons & $16(8 \%)$ & $10(9 \%)$ & $6(7 \%)$ \\
\hline \multicolumn{4}{|l|}{ SCN9A rs7607967 } \\
\hline GG & $24(13 \%)$ & $15(14 \%)$ & $9(11 \%)$ \\
\hline GA & $84(45 \%)$ & $43(40 \%)$ & $41(53 \%)$ \\
\hline AA & $78(42 \%)$ & $50(46 \%)$ & $28(36 \%)$ \\
\hline \multicolumn{4}{|l|}{ SCN9A rs12994338 } \\
\hline$\pi$ & $13(7 \%)$ & $9(8 \%)$ & $4(5 \%)$ \\
\hline $\mathrm{TC}$ & $80(43 \%)$ & $46(43 \%)$ & $34(44 \%)$ \\
\hline $\mathrm{CC}$ & $93(50 \%)$ & $53(49 \%)$ & $40(51 \%)$ \\
\hline \multicolumn{4}{|l|}{ SCN9A rs13017637 } \\
\hline$\pi$ & $3(2 \%)$ & $1(1 \%)$ & $2(3 \%)$ \\
\hline
\end{tabular}


Table 1 Patient characteristics (Continued)

\begin{tabular}{llll}
\hline & All patients & Cases & $\begin{array}{c}\text { Control } \\
\text { TIPN Gr 0-1 } \\
(N=78)\end{array}$ \\
TC & TIPN Gr 2-3 & $(\mathrm{N}=108)$ & $21(27 \%)$ \\
CC & $37(20 \%)$ & $16(15 \%)$ & $55(70 \%)$ \\
SCN10A rs12632942 & $146(78 \%)$ & $91(84 \%)$ & $16(20 \%)$ \\
GG & & $28(26 \%)$ & $38(49 \%)$ \\
GA & $44(24 \%)$ & $49(45 \%)$ & $24(31 \%)$ \\
AA & $87(47 \%)$ & $31(29 \%)$ & $1(1 \%)$ \\
SCN10A rs6795970 & $55(29 \%)$ & $3(3 \%)$ & $22(28 \%)$ \\
AA & & $25(23 \%)$ & $55(71 \%)$ \\
AG & $4(2 \%)$ & $80(74 \%)$ & \\
GG & $47(25 \%)$ & $135(73 \%)$ & \\
\hline Ca. & & \\
\hline
\end{tabular}

${ }^{a}$ Ca. cancer, ${ }^{b} A C$ cyclophosphamide $\left(600 \mathrm{mg} / \mathrm{m}^{2}\right)$ and doxorubicin $\left(60 \mathrm{mg} / \mathrm{m}^{2}\right), C E F$ cyclophosphamide $\left(500 \mathrm{mg} / \mathrm{m}^{2}\right)$ with epirubicin $\left(100 \mathrm{mg} / \mathrm{m}^{2}\right)$ and 5 fluorouracil $\left(500 \mathrm{mg} / \mathrm{m}^{2}\right), \mathrm{f} / \mathrm{b}$ followed by, PTX paclitaxel, DTX docetaxel, CPA +DTX four cycles of cyclophosphamide $\left(600 \mathrm{mg} / \mathrm{m}^{2}\right.$, day 1$)$ and docetaxel $\left(75 \mathrm{mg} / \mathrm{m}^{2}\right.$, day 1) every 3 weeks, dose dense TC paclitaxel $\left(80 \mathrm{mg} / \mathrm{m}^{2}\right.$, day $\left.1,8,15\right)$ and carboplatin $(A U C 6$, day 1$)$ every 3 weeks, Tri TC six cycles of paclitaxel $\left(175 \mathrm{mg} / \mathrm{m}^{2}\right)$ and carboplatin (AUC6, day 1) every 3 weeks, ${ }^{\mathrm{C}} \mathrm{TIPN}$ taxane-induced peripheral neuropathy

SCN9A rs7607067, SCN9A rs12994338, SCN9A rs13017637, SCN10A rs12632942, and SCN10A rs6795970 represent polymorphisms

inherited erythromelalgia and paroxysmal extreme pain disorder, rare familial diseases associated with excruciating pain [26-28]. In contrast, loss-of-function mutations cause congenital pain insensitivity, a rare autosomal recessive disease [26, 27]. Rare missense variants have also been reported in SCN9A [29,30] and SCN1OA [30, 31 in patients with painful small fiber neuropathy. It is

Table 2 SNPs correlate with severity of TIPN† (grade $0-1 \mathrm{vs.}$ grade $2-3$ ) in all patients and in breast cancer patients (subset analysis), and SNPs correlate with TIPN (grade 0-1 vs. grade 23) at 1 year after completion of taxane treatment in all patients

\begin{tabular}{lllll}
\hline Gene & SNP & Odds ratio & Odds ratio (95\% C.I. $\left.{ }^{\text {b }}\right)$ & $P$-value \\
\hline SCN9A & rs7607967 & 1.749 & $0.889-3.441$ & 0.1054 \\
& rs12994338 & 0.952 & $0.492-1.841$ & 0.8836 \\
& rs13017637 & 3.463 & $1.456-8.237$ & 0.0050 \\
SCN10A & rs12632942 & 1.024 & $0.498-8.237$ & 0.9491 \\
& rs6795970 & 0.949 & $0.450-1.998$ & 0.8894
\end{tabular}

A subset analysis in Breast only

$\begin{array}{lllll}\text { SCN9A } & \text { rs7607967 } & 1.822 & 0.864-3.842 & 0.1151 \\ & \text { rs12994338 } & 0.913 & 0.442-1.888 & 0.8061 \\ & \text { rs13017637 } & 5.053 & 1.743-14.641 & 0.0029 \\ \text { SCN10A } & \text { rs12632942 } & 1.262 & 0.569-2.802 & 0.567 \\ & \text { rs6795970 } & 1.135 & 0.515-2.501 & 0.7537\end{array}$

Analysis at 1 year after completion of taxane treatment in all patients

\begin{tabular}{lllll} 
SCN9A & rs7607967 & 0.735 & $0.313-1.728$ & 0.4805 \\
& rs12994338 & 0.952 & $0.418-2.167$ & 0.9069 \\
& rs13017637 & 3.906 & $1.084-14.075$ & 0.03719 \\
SCN10A & rs12632942 & 0.560 & $0.219-1.430$ & 0.225 \\
& rs6795970 & 1.834 & $0.697-4.826$ & 0.2192 \\
\hline
\end{tabular}

${ }^{\mathrm{a}}$ TIPN taxane-induced peripheral neuropathy, ${ }^{\mathrm{b}} \mathrm{C} . \mathrm{I}$. confidence interval thought that enhanced Nav channel activity might directly contribute to pain experienced by these patients because several identified missense variants exerted GOF effects in cell-based electrophysiology assays [32]. Our findings indicate that $S C N 9 A$-rs 13017637 is a risk factor for TIPN severity. However, the function of SCN9Ars13017637 is not known. SCN10A-rs6795970 reportedly affects human pain sensitivity. A recent study suggested that SNPs in voltage-gated sodium channel genes (SCN9A-rs6754031 and SCN10A-rs12632942) can cause oxaliplatin-based peripheral neurotoxicity $[24,25,33$, 34]. A polymorphism in $S C N 9 A$ (rs6746030) was also reported to be associated with decreased neurotoxicity [35]. However, these polymorphisms were not associated with TIPN in our study. Thus, there could be different predisposing polymorphisms for different ethnic groups. Moreover, a selective Nav1.7 channel blocker was shown to decrease firing frequency in the human DRG with spontaneous action potentials. This suggests that Nav1.7 might be a potential new target for TIPN treatment [19]. However, these results must be validated by larger and prospective studies.

There were some limitations to this study. First, we focused on paclitaxel or docetaxel as taxane regimens. There might be possible differences between paclitaxel and docetaxel regarding the severity or duration of PN. Moreover, platinum added to taxane might influence PN because it was reported as a risk factor for chemotherapy-induced PN [36]. Second, although cumulative drug doses were different, no adjustments were made for multiplicity of inferences. However, differences in cumulative doses were small and would be less likely to influence TIPN development. Third, our study focused on SCN9A and SCN10A, which were evaluated based on previous studies; other 
sodium channel subunits such as Nav1.9 were not evaluated. Fourth, there was a possible issue with type I error for this study because of multiple test.

\section{Conclusion}

TIPN was associated with SCN9A-rs13017637 in Japanese breast or ovarian cancer patients who received taxane. This finding is highly exploratory and requires replication and validation prior to any consideration of clinical use.

\section{Abbreviations}

TIPN: Taxane Induced Peripheral Neuropathy; VGSCs: Voltage Gated Sodium Channels; DRG: Dorsal Root Ganglion; SCNA: Synuclein alpha; PN: Peripheral Neuropathy; AC: Doxorubicin and Cyclophosphamide;

CEF: Cyclophosphamide and Epirubicin and 5-Fluorouracil;

CPA: Cyclophosphamide; DTX: Docetaxel; TC: Carboplatin and Paclitaxel; ORs: Odds ratios; Cis: Confidence intervals; HWE: Hardy Weinberg Equilibrium; GOF: Gain Of Function

\section{Acknowledgments}

We thank Ms. Masayo Kawamura, Ms. Nao Nakamura, Ms. Kiyomi Nonogaki, and Ms. Hitomi Sato for helping with data collection.

\section{Authors' contributions}

YT contributed to collecting data and writing the manuscript. YT, CS and DN was a major contributor in analyzing and interpreting the patient data. JH contributed to collecting data. $\mathrm{KH}$ contributed the design of this work. SS and $\mathrm{Kl}$ contributed the interpretation of data. AS, YO, NT, MY, KY, TT, HK, KT and $Y F$ contributed the draft of this work and revisions. All authors read and approved the final manuscript.

\section{Funding}

This work was supported by a Scientific Research Grant from the Ministry of Health, Labor, and Welfare (H21-021), the National Cancer Center Research and Development Fund (23-A-30, 26-A-20), and a study grant from Okinaka Memorial Institute for Medical Disease (No. 2018-23). The role of the funding body: in collection of data, analysis software and writing the manuscript.

\section{Availability of data and materials}

The datasets used and analyzed during the current study are available from the corresponding author on reasonable request.

\section{Ethics approval and consent to participate}

All patients provided written informed consent for adjuvant treatment and DNA collection for genetic analysis. The study was conducted in accordance with the Declaration of Helsinki and was approved by the institutional review board of National Cancer Center Hospital and Toranomon Hospital. (protocol number: 2013-199).

\section{Consent for publication}

Not applicable.

\section{Competing interests}

The authors have no competing interests to declare.

\footnotetext{
Author details

${ }^{1}$ Department of Breast and Medical Oncology, National Cancer Center Hospital, 5-1-1 Tsukiji, Chuo-ku, Tokyo 104-0045, Japan. ${ }^{2}$ Department of Medical Oncology, Toranomon Hospital, 2-2-2 Toranomon, Minato-ku, Tokyo 105-8470, Japan. ${ }^{3}$ Department of Anesthesiology, Kohnodai Hospital, National Center for Global Health and Medicine, 1-7-1, Kohnodai, Ichikawa-shi, Chiba 272-8516, Japan. ${ }^{4}$ Addictive Substance Project, Tokyo Metropolitan Institute of Medical Science, 2-1-6 Kamikitazawa, Setagaya-ku, Tokyo 156-8506, Japan. ${ }^{5}$ Department of Breast and Endocrine Surgery, Toranomon Hospital, 2-2-2 Toranomon, Minato-ku, Tokyo 105-8470, Japan. ${ }^{6}$ Department of Breast Medical Oncology, Comprehensive Cancer Center, National Center for Global Health and Medicine, 1-21-1 Toyama, Shinjuku-ku, Tokyo 162-8655, Japan.
}

Received: 27 November 2019 Accepted: 6 April 2020

Published online: 16 April 2020

\section{References}

1. Sparano JA, Wang M, Martino S, et al. Weekly paclitaxel in the adjuvant treatment of breast cancer. N Engl J Med. 2008;358:1663-71.

2. Vasey PA, Jayson GC, Gordon A, et al. Scottish Gynaecological Cancer trials group. Phase III randomized trial of docetaxel-carboplatin versus paclitaxelcarboplatin as first-line chemotherapy for ovarian carcinoma. J Natl Cancer Inst. 2004;96:1682-91.

3. Tanabe Y, Hashimoto K, Shimizu C, et al. Paclitaxel-induced peripheral neuropathy in patients receiving adjuvant chemotherapy for breast cancer. Int J Clin Oncol. 2013;18:132-8.

4. Lee JJ, Swain SM. Peripheral neuropathy induced by microtubule-stabilizing agents. J Clin Oncol. 2006:24:1633-42.

5. Gréen $H$, Söderkvist $P$, Rosenberg $P$, et al. Pharmacogenetic studies of paclitaxel in the treatment of ovarian cancer. Basic Clin Pharmacol Toxicol. 2009:104:130-7.

6. Sissung TM, Baum CE, Deeken J, et al. ABCB1 genetic variation influences the toxicity and clinical outcome of patients with androgen-independent prostate cancer treated with docetaxel. Clin Cancer Res. 2008;14:4543-9.

7. Tanabe Y, Shimizu C, Hamada A, et al. Paclitaxel-induced sensory peripheral neuropathy is associated with an ABCB1 single nucleotide polymorphism and older age in Japanese. Cancer Chemother Pharmacol. 2017;79:1179-86.

8. de Graan AJ, Elens L, Sprowl JA, et al. CYP3A4*22 genotype and systemic exposure affect paclitaxel-induced neurotoxicity. Clin Cancer Res. 2013:19: 3316-24.

9. Hertz DL, Roy S, Motsinger-Reif AA, et al. CYP2C8*3 increases risk of neuropathy in breast cancer patients treated with paclitaxel. Ann Oncol. 2013;24:1472-8

10. Leskelä S, Jara C, Leandro-García LJ, et al. Polymorphisms in cytochromes P450 2C8 and 3A5 are associated with paclitaxel neurotoxicity. Pharmacogenomics J. 2011;11:121-9.

11. Baldwin RM, Owzar K, Zembutsu H, et al. A genome-wide association study identifies novel loci for paclitaxel-induced sensory peripheral neuropathy in CALGB 40101. Clin Cancer Res. 2012;18:5099-109.

12. Abraham JE, Guo Q, Dorling $L$, et al. Replication of genetic polymorphisms reported to be associated with taxane-related sensory neuropathy in patients with early breast cancer treated with paclitaxel. Clin Cancer Res. 2014;20:2466-75.

13. Flatters SJ, Bennett GJ. Studies of peripheral sensory nerves in paclitaxelinduced painful peripheral neuropathy: evidence for mitochondrial dysfunction. Pain. 2016;122:245-57.

14. Peters CM, Jimenez-Andrade JM, Kuskowski MA, Ghilardi JR, Mantyh PW. An evolving cellular pathology occurs in dorsal root ganglia, peripheral nerve and spinal cord following intravenous administration of paclitaxel in the rat. Brain Res. 2007;1168:46-59.

15. Akopian AN, Souslova V, England S, et al. The tetrodotoxin-resistant sodium channel SNS has a specialized function in pain pathways. Nat Neurosci. 1999;2:541-8.

16. Yu FH, Catterall WA. Overview of the voltage-gated sodium channel family. Genome Biol. 2003:4:207.

17. Vargas-Alarcon G, Alvarez-Leon E, Fragoso JM, et al. A SCN9A gene-encoded dorsal root ganglia sodium channel polymorphism associated with severe fibromyalgia. BMC Musculoskelet Disord. 2012;13:23.

18. Catterall WA. From ionic currents to molecular mechanisms: the structure and function of voltage-gated sodium channels. Neuron. 2000; 26:13-25.

19. Li Y, North RY, Rhines LD, et al. DRG voltage-gated sodium channel 1.7 is up-regulated in paclitaxel-induced neuropathy in rats and in humans with neuropathic pain. J Neurosci. 2018;38:1124-36.

20. Xia Z, Xiao Y, Wu Y, Zhao B. Sodium channel Nav1.7 expression is upregulated in the dorsal root ganglia in a rat model of paclitaxel-induced peripheral neuropathy. Springerplus. 2016;5:1738 eCollection.

21. Chen AP, Setser A, Anadkat MJ, et al. Grading dermatologic adverse events of cancer treatments: the common terminology criteria for adverse events version 4.0. J Am Acad Dermatol. 2012:67:1025-39.

22. Duan G, Xiang G, Guo S, et al. Genotypic analysis of SCN9A for prediction of postoperative pain in female patients undergoing gynecological laparoscopic surgery. Pain Physician. 2016;19:E151-62. 
23. Duan G, Guo S, Zhang Y, et al. The effect of SCN9A variation on basal pain sensitivity in the general population: an experimental study in young women. J Pain. 2015;16:971-80.

24. Argyriou AA, Cavaletti G, Antonacopoulou A, et al. Voltage-gated sodium channel polymorphisms play a pivotal role in the development of oxaliplatin-induced peripheral neurotoxicity: results from a prospective multicenter study. Cancer. 2013;119:3570-7.

25. Wadhawan $\mathrm{S}$, Pant $\mathrm{S}$, Golhar R, et al. NaV channel variants in patients with painful and nonpainful peripheral neuropathy. Neurol Genet. 2017;3:e207.

26. Vetter I, Deuis JR, Mueller A, et al. NaV1.7 as a pain target-from gene to pharmacology. Pharmacol Ther. 2017;172:73-100.

27. Dib-Hajj SD, Yang Y, Black JA, Waxman SG. The Na(V) 1.7 sodium channel: from molecule to man. Nat Rev Neurosci. 2013;14:49-62.

28. Tang Z, Chen Z, Tang B, Jiang H. Primary erythromelalgia: a review. Orphanet J Rare Dis. 2015;10:127.

29. Faber CG, Hoeijmakers JG, Ahn HS, et al. Gain of function NaV1.7 mutations in idiopathic small fiber neuropathy. Ann Neurol. 2012;71:26-39.

30. Brouwer BA, Merkies IS, Gerrits MM, Waxman SG, Hoeijmakers JG, Faber CG. Painful neuropathies: the emerging role of sodium channelopathies. J Peripher Nerv Syst. 2014;19:53-65.

31. Faber CG, Lauria G, Merkies IS, et al. Gain-of-function NaV1.8 mutations in painful neuropathy. Proc Natl Acad Sci U S A. 2012:109:19444-9.

32. Hoeijmakers JG, Faber CG, Merkies IS, Waxman SG. Painful peripheral neuropathy and sodium channel mutations. Neurosci Lett. 2015:596:51-9.

33. Adelsberger H, Quasthoff S, Grosskreutz J, Lepier A, Eckel F, Lersch C. The chemotherapeutic oxaliplatin alters voltage-gated $\mathrm{Na}(+)$ channel kinetics on rat sensory neurons. Eur J Pharmacol. 2000;406:25-32.

34. Palugulla S, Thakkar DN, Kayal S, Narayan SK, Dkhar SA. Association of voltage-gated sodium channel genetic polymorphisms with oxaliplatininduced chronic peripheral neuropathy in south Indian cancer patients. Asian Pac J Cancer Prev. 2017;18:3157-65.

35. Sereno M, Gutiérrez-Gutiérrez G, Rubio JM, et al. Genetic polymorphisms of SCN9A are associated with oxaliplatin-induced neuropathy. BMC Cancer. 2017;17:63.

36. Avan A, Postma TJ, Ceresa C, et al. Platinum-induced neurotoxicity and preventive strategies: past, present, and future. Oncologist. 2015;20:411-32.

\section{Publisher's Note}

Springer Nature remains neutral with regard to jurisdictional claims in published maps and institutional affiliations.

Ready to submit your research? Choose BMC and benefit from:

- fast, convenient online submission

- thorough peer review by experienced researchers in your field

- rapid publication on acceptance

- support for research data, including large and complex data types

- gold Open Access which fosters wider collaboration and increased citations

- maximum visibility for your research: over $100 \mathrm{M}$ website views per year

At $\mathrm{BMC}$, research is always in progress.

Learn more biomedcentral.com/submissions 